\title{
Hays, Marinero, and Thompson to Chair 1991 MRS Spring Meeting
}

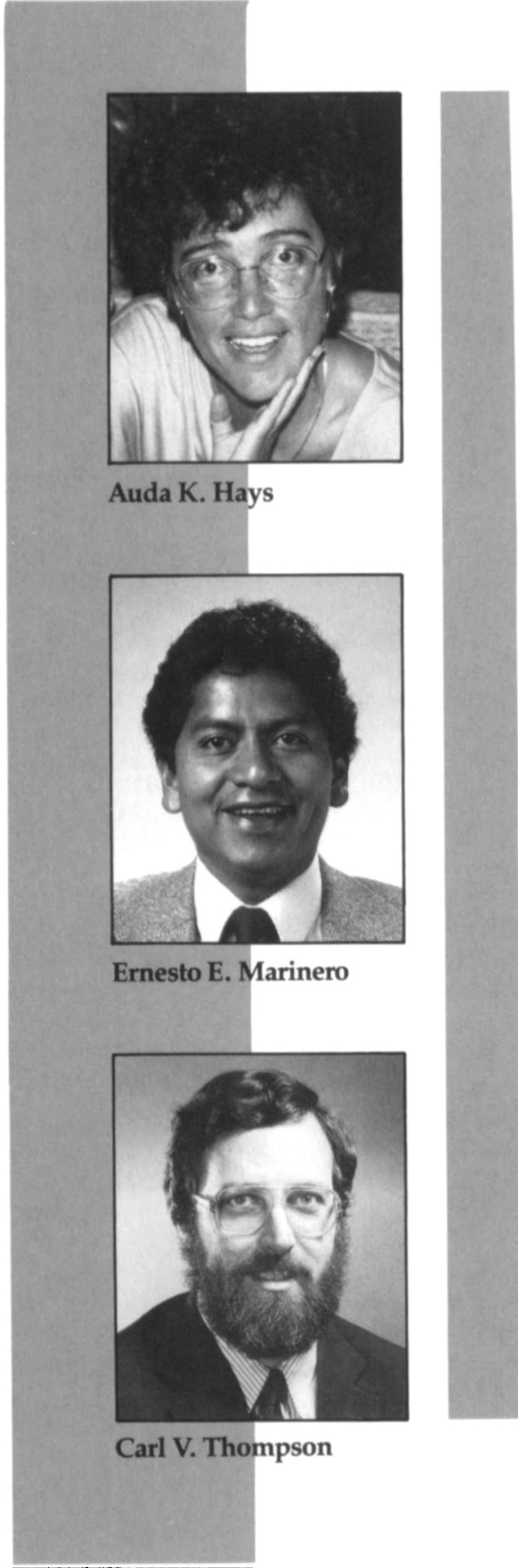

Auda K. Hays of Sandia National Laboratories, Ernesto E. Marinero from IBM's Almaden Research Center, and Carl V. Thompson of the Massachusetts Institute of Technology will serve as Meeting Chairs for the 1991 MRS Spring Meeting, April 29 - May 4 in Anaheim, California. The Spring Meeting agenda already lists 23 technical symposia plus a series of complementary short courses (see p. 68-69 in this issue).
Abstracts are being solicited on farranging, multidisciplinary aspects of microelectronics, polymers, and thin film interfaces. Other topics span materials for optical information processing, molecular tribology, high $T_{c}$ superconducting interfaces, molecular sieve materials, and thermoelectrics and related materials. Three symposia on microelectronics-related subjects will emphasize materials reliability issues, a topic of considerable interest in light of industrial competitiveness. Extensive international participation is being planned for the areas of amorphous silicon technology and magnetic materials.

"We expect a great deal of interest to be generated by a new symposium on 'Environmentally Conscious Materials Processing,"' says Meeting Chair A.K. Hays. "This symposium will deal with research and development issues related to U.S. industry's need to respond to growing pressure, both public and private, to minimize the impact of large-scale manufacturing on the environment."

Auda K. Hays is supervisor of the Surface Engineering and Thin Film Technology Division at Sandia National Laboratories, Albuquerque, New Mexico. She has more than 25 years of research experience, with emphasis on energy transfer in solids and gases; the development of highpower, ultraviolet lasers; and the development of plasma deposition and etching processes. She began her career as a research assistant while working toward a BS degree in chemistry at the University of Texas, Austin. After earning her degree in 1967, Hays moved on to the University of California, Berkeley, where she worked as a graduate research assistant, earning her MS degree in chemistry in 1969 . It was then on to the University of California at Los Angeles, where Hays again worked as a graduate research assistant, earning a $\mathrm{PhD}$ in physical chemistry in 1974. Following this, she joined Sandia National Laboratories as a member of the technical staff. She eventually became supervisor in the Interfacial Chemistry and Coating Research Division before moving to her present position. Hays, a member of the Materials Research Society and the American Vacuum Society, received the American Vacuum Society's R.F. Bunshah Award in 1986.

Ernesto E. Marinero manages the Advanced Media Department in the Optical Storage Laboratory at the IBM Almaden Research Center, San Jose, California. After completing $\mathrm{BSc}$ and $\mathrm{PhD}$ degrees in physics at Heriot-Watt University in Edin- burgh, Marinero became a staff member of the Max-Planck Institute fur Biophysikalische Chemic in Goettingen. There his research involved laser physics, photochemistry, spectroscopy, and picosecond studies. In 1981, he joined Stanford University's Chemistry Department, where his research involved the determination of the quantum states of molecular hydrogen produced in hydrogen-exchange reactions utilizing transient laser techniques, the generation of VUV coherent radiation, and the application of excimer lasers in lithography. Since joining IBM in 1983, Marinero's work has focused on thin film materials, including nonlinear photochemistry in polymer films, phase transformations in chalcogenide alloys and, more recently, amorphous and multilayered magneto-optic thin films. Marinero is a member of MRS, APS, IEEE, AVS and the Royal Society of Chemistry of London. He co-chaired an MRS symposium on ultrathin magnetic films and also the $1990 \mathrm{E}$ MRS Spring Meeting symposium on magnetic thin films and multilayers. $\mathrm{He}$ has also served on the organizing committee of the International Laser Science Conference.

Carl V. Thompson is a tenured associate professor of electronic materials in the Materials Science and Engineering Department at the Massachusetts Institute of Technology. Before becoming a professor, he acquired a wide range of work/research experience in both the corporate world, with companies such as General Electric and U.S. Steel, and the educational field, with universities such as Harvard, Yale, and MIT. The author of numerous papers, Thompson also does consulting work and has lectured worldwide. He received a BS degree in materials science and engineering from MIT in 1976, and MS and PhD degrees in applied physics from Harvard University in 1977 and 1982, respectively. In 1983, he returned to MIT as a postdoctoral research associate and IBM postdoctoral fellow. In this position, his research covered surface-energy-driven secondary grain growth and solid-state grapho-epitaxy in semiconductor thin films. As a professor, his research and teaching have concentrated on studies in electronic materials with emphasis on thin film processing and properties; microstructural evolution in polycrystaline and epitaxial films; siliconon-insulator, interconnects, and reactions in multilayer films; fabrication, properties, and stability of very small $(<100 \mathrm{~nm})$ structures. 